\title{
Demand for health risk reductions: A cross-national comparison between the U.S. and Canada
}

\author{
Trudy Ann Cameron • J. R. DeShazo • Peter Stiffler
}

Published online: 13 October 2010

C The Author(s) 2010. This article is published with open access at Springerlink.com

\begin{abstract}
Using a large stated preference survey conducted across the U.S. and Canada, we assess differences in individual willingness to pay (WTP) for health risk reductions between the two countries. Our utility-theoretic choice model allows for systematically varying marginal utilities for avoided future time in different adverse health states (illness-years, recovered/remission years, and lost life-years). We find significant differences between Canadian and U.S. preferences. WTP also differs systematically with age, gender, education, and marital status, as well as a number of attitudinal and subjective health-perception variables. Age profiles for WTP are markedly different across the two countries. Canadians tend to display flatter age profiles, with peak WTP realized at older ages.
\end{abstract}

Keywords Willingness to pay for a microrisk reduction - Value of a statistical life $(V S L) \cdot$ Stated preference $\cdot$ Health risks $\cdot$ International comparison

\section{JEL classification Q51 I18}

Are there differences between the U.S. and Canada in how people value new programs that reduce their health risks? If so, how large are these differences? Which factors explain the observed differences? Specifically, are they explained simply by differences in the socio-economic characteristics of people in each county? Or are they due to subtle differences in basic preferences for risk protection? Or are they due to measurable differences in individual health beliefs that arise from differences in health care systems? If such beliefs are correlated with health care systems, they

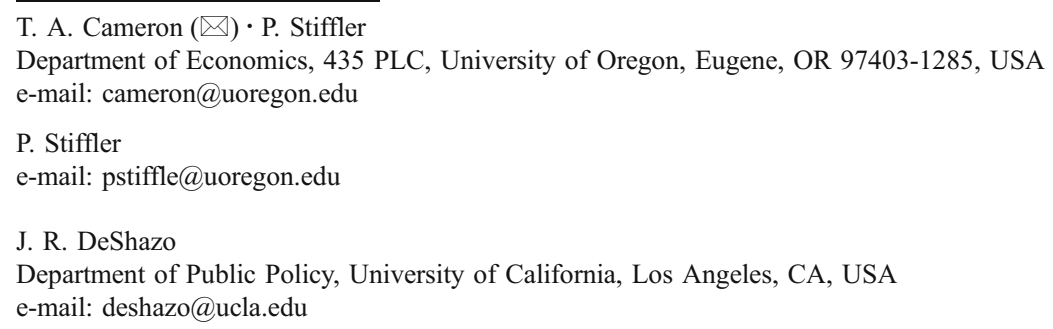


may shift individuals' demands for privately available risk mitigation programs in several ways. For example, they may influence individuals' beliefs about their subjective risks of experiencing various illnesses. They may also determine whether a privately available risk reducing program is viewed as a substitute for, or as a complement to, the individual's existing health care system. Do such beliefs differ across Canada and the U.S. and, if so, do they co-vary with demand for risk reductions? In this paper, we offer initial answers to these questions through a comparative analysis of demand for health risk reductions in both countries. Our analysis should help researchers better understand, and perhaps anticipate, shifting demand patterns for health risk management as Canada experiments with greater privatization while the U.S. expands access to its publicly funded health care system.

Utilizing individual stated-preference data from virtually identical generalpopulation surveys conducted in both Canada and the United States, we estimate models that investigate differences in average WTP for health risk reductions across the two countries. ${ }^{1}$ In each country, we present respondents with sets of illnessspecific risk reduction programs for most of the major illnesses from which people die. These programs involve diagnostic screening and, when illness risks are high, medical therapies that would reduce their probability of experiencing that particular future illness profile. Respondents pay an annual fee to participate in each riskreducing program. Our estimated models permit us to recover the implicit marginal value of a sick-year or a lost life-year, as in a hedonic model.

As described in Section 1, the surveys we use collected data on numerous determinants of WTP that are likely to vary between the U.S. and Canada, but which would not be available using only hedonic wage-risk data for the two countries. ${ }^{2}$ For example, the value of these risk-reduction programs should vary with the individuals' subjective risks of each type of illness. WTP for these additional riskreduction programs, which are described as being ineligible for coverage by health insurance, should also vary with the individuals' assessments of their opportunities for averting behaviors (reduction in smoking, weight, more regular doctor visits, etc.) which the individual could also (or alternatively) use to reduce their health risks. Since the offered risk mitigation programs would be purchased outside of respondents' current health plans, WTP may also vary with their past experience in going outside of their health plans. WTP for health risk reduction should also vary with individuals' perceptions of the effectiveness of the health care services that their current plans could provide - both because current risk levels can be reduced ex ante through preventive care and prospective illnesses can be more effectively treated.

Accounting for this kind of individual heterogeneity is important for several reasons. First, controls for these individual characteristics are necessary to prevent cross-national heterogeneity from showing up as spurious generic cross-national differences (or a lack thereof) in health preferences. Second, any WTP number used

\footnotetext{
${ }^{1}$ Although stated preference methods have generated controversy in the past because of concerns that people would overstate their willingness to pay for a public risk reduction, over the past ten years important strides have been made in understanding and minimizing concerns about their incentive compatibility (List 2001). Indeed, meta-analyses have tended to show that stated preference estimates of the demand for health risk reductions are systematically lower than those produced by revealed preference data (Kochi et al. 2006).

${ }^{2}$ Wage-risk studies are the predominant revealed-preference method for estimating the marginal rate of substitution between mortality risks and money.
} 
for benefit-cost analysis should reflect the actual distribution of characteristics in the at-risk population for a particular policy.

As we discuss in Section 2, based on the detailed attitudinal and subjective health perception variables collected in our survey, we have identified a number of variables for which the distribution (especially in relation to age) appears to differ between the U.S. and Canada. For example, members of our Canadian sample appear to express higher subjective probabilities associated with the risk of heart disease, cancers, respiratory disease, diabetes, and Alzheimer's disease. They are also more inclined to say they could improve their health by quitting smoking and improving their diet, but they are less inclined to believe they can reduce their risk of traffic accidents through increased use of seat belts. Depending on age, they feel they have more or less opportunity to improve their health by exercising more.

Given the different health-care institutions in the two countries - universal coverage through provincial health plans in Canada, and the private-payer system with partial coverage in the United States - individual perceptions can presumably differ about the efficacy of health care and its overall accessibility. Our survey elicits information about each individual's confidence in diagnosis and treatment under their respective health care systems. Moreover, the health risk reduction programs used in our stated choice scenarios for Canadians were stipulated as being outside the normal course of care under the provincial health plans, so information was also collected from each individual about their personal experience with instances where they may have gone outside their provincial health plan for prior medical diagnostic and testing services.

Section 3 outlines the utility-theoretic discrete choice model used in estimation. This model is innovative in that it specifically includes latencies, sick-years, recovered/ remission-years and lost life-years associated with different prospective illness profiles for which the individual may reduce their risk through purchase of a diagnostic test and preventive treatments. Across choice sets, we vary the mix of attributes for the different health risks and the resulting data permit us to estimate distinct marginal utilities associated with discounted time in each health state. This marginal utility information can be used to derive a corresponding inverse demand function for reductions in the risk of experiencing a wide variety of different illness profiles.

Cross-country studies, such as this one, are typically motivated by one (or the other) of two kinds of potential findings. Studies may reveal heretofore unknown differences in the determinants of demand across the countries under study or they may illuminate commonalities where differences were anticipated based on casual empiricism. In Section 4, we control for age, gender, educational attainment and marital status, as well as subjective health risks and several attitudinal variables, but we still find numerous significant differences between Canadian and U.S. respondents in the marginal value of risk reduction programs. In particular, the effect of respondent age seems to differ substantially across the two countries. However, peak WTP over age for Canadian males is much more similar to peak WTP for U.S. males for those Canadians who have prior experience with out-of-plan diagnostic testing (although the timing of the peaks remains different). ${ }^{3}$

\footnotetext{
${ }^{3}$ Subjective health risks and health-related attitudes may be endogenous. Certainly, out-of-plan experience is endogenous. These different preferences could account for why a particular respondent has gone outside the provincial health care system in the past.
} 
In Section 5, we control for differences in income distributions across the two countries and use simulation methods based on the joint distribution of our estimated parameters to explore the influence of differences in attitudes and subjective health perceptions on demand for mortality risk reductions specifically. The age profile of WTP to reduce the risk of sudden death in the current period (the specific risk reduction that maps most closely to measures estimated in the conventional literature) seems to be remarkably different across the two countries. Canadians have a flatter age profile of WTP to reduce risk of sudden death in the current period, with peak WTP realized at a substantially older age (about 60 for Canadians compared to about 35-40 for the U.S. sample). In this section, we also compare our findings to those of other researchers (e.g. Aldy and Viscusi (2008)) who have examined age profiles in willingness to pay for the U.S., both overall and per discounted lost life-year.

Apparently only one previously published study has directly compared WTP for health risk reductions between the U.S. and Canada. ${ }^{4}$ Alberini et al. (2004) studied a sample of respondents from Hamilton, Ontario, and compared them to another sample from the U.S. They find that Canadians have lower WTP, at least for those aged 40 years and older. Although the Alberini et al. study allows for systematic variation with age, the differences in WTP are not explained through systematic variation across other sociodemographic characteristics, subjective risks of the diseases in question, or differences between the Canadian and U.S. health care systems. We extend this nascent cross-national literature to explain observed differences in individual $W T P$ for health risk reduction programs by allowing for individual demand heterogeneity with respect to each of these factors. 5

In addition to the Alberini et al. work, there is an unpublished paper by Chestnut et al. (2009) that also explores differences between the U.S. and Canada. Our work is differentiated from this other study in that we employ greater utility-theoretic structure in our model of preferences. Their study considers four types of health threats, but does not model the future time profiles of symptoms associated with these illnesses or injuries, nor does it distinguish between different types of health states. Age is captured only as an indicator for the respondent being over 75 years old. Due to the nature of their data, they devote considerably more attention to the two different elicitation methods used in their study. Canadian and U.S. models are estimated completely independently, and they conclude that none of the differences in $W T P$ across the two countries are statistically significant after adjusting for

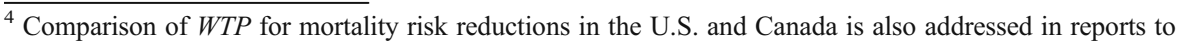
Cornell University and Health Canada from a study by Stratus Consulting. See Chestnut et al. (2003, 2004).

${ }^{5}$ See Hammitt (2007) for an exposition on the opportunity for inclusion of systematic variation in WTP studies. In addition to Alberini et al. (2004), Krupnick et al. (2002) identify variation in WTP across age of the individuals, showing weak support for the notion that WTP for health risk reductions declines with age. This is evidence of a "life-cycle effect," where individuals expect to derive increasing marginal utility from reducing health risks that come to bear later in their lives. In addition to the "life cycle effect," DeShazo and Cameron (2005) find statistical evidence that as people age, there is a systematic downward shift in their anticipated schedule of marginal utility for risk reductions at future ages. Taken together, these two effects offer evidence of time inconsistency: at younger ages, individuals seem to value future health more, however, as they get older, they value future health less.
} 
currency differences. In contrast, we find statistically significant differences in preferences and differing age profiles for WTP.

\section{Survey design and data}

Our two surveys, administered to general-population samples in the U.S. and Canada, used survey instruments that were virtually identical (except for the randomized portions which differed across choice occasions and across individuals). This ensures that any observed differences in demand estimates across the two countries are not artifacts solely of different survey questions or systematic sampling. This stated preference survey was conducted first for Canadian residents using the internet consumer panel maintained by Ipsos-Reid (selected so that the proportions of the sample in different sociodemographic groups mimic the general population). It was conducted again, a few months later, for the United States using the representative consumer panel maintained by Knowledge Networks, Inc. The administration of the Canadian survey allowed for collection of key demographic information for Canadians that mirrors the demographic characteristics included in Knowledge Network's standing consumer panel for the United States. Information on respondent age, income, educational attainment, marital status and gender is available for both samples. The U.S. sample has been employed in Cameron and DeShazo (2009), so only the highlights of the survey and sample properties will be reviewed here. ${ }^{6}$

In addition to demographic characteristics, this survey collects four other categories of information from each respondent. First, information is sought concerning the individual's personal health history and their perceptions of their likely susceptibility to specific categories of major health risks. These questions ask about the respondent's own prior experience with the particular types of illnesses that they will subsequently be asked to consider in a set of conjoint choice experiments. Respondents are also asked about the prior experiences of friends and family members with these illnesses, about the extent to which they believe these disease risks can be controlled through health habits and lifestyle choices, and about their personal room to improve their health habits along seven dimensions - including opportunities to see the doctor more regularly, to lose weight, to exercise more, to drink less alcohol, to use a seat belt more, to eat a healthier diet, and to quit smoking. ${ }^{7}$

\footnotetext{
${ }^{6}$ For more information on the Cameron and DeShazo (2009) survey instrument and the U.S. sample of data, see the comprehensive appendices which accompany that paper: Appendix A - Survey Design \& Development, Appendix B - Stated Preference Quality Assurance and Quality Control Checks, Appendix C - Details of the Choice Set Design, Appendix D - The Knowledge Networks Panel and Sample Selection Corrections, Appendix E - Model, Estimation and Alternative Analyses, and Appendix F Estimating Sample Codebook.

${ }^{7}$ Although the nominal life expectancies used in the illness profiles for the survey's choice experiments were based upon actuarial life expectancies, we found in pre-tests that we had to add about eight years to these actuarial expectancies to make them plausible. People tend to discount the age at death for relatives who "died young" and to focus instead on their longest-living parents or grandparents. Respondents were asked, at the end of the survey, to report their individual subjective life expectancy based on their health and family history. (Our estimating specifications control for departures between individual's subjective life expectancy and the nominal life expectancy quoted in that individual's choice questions.)
} 
The second part of the survey provides a risk tutorial and trains respondents about how to interpret each of the attributes of the different risk reduction programs that form the core of the survey. Respondents are required to answer a simple skilltesting question to evaluate their comprehension of the notion of risk, since risk comprehension is crucial to the choice tasks.

In the third and main section of the survey, after 24 pages of tutorials and preparation, each respondent is presented with the first of five independent choice scenarios. The first choice scenario presents all of the same quantitative information used in the tutorial section in a simplified one-page "choice table." See Fig. 1 for an example. ${ }^{8}$ The individual is asked to evaluate two health programs, each offering a reduction in a specified health risk at a monthly cost, against the status quo alternative (i.e. no health risk reduction program, but no expense either). The respondent is then asked to choose their most preferred option among the three options available. Conditional on the respondent's gender and current age, which were known in advance, each of the two offered health programs involves a randomly assigned reduction in the probability of getting sick or injured, and describes the expected time-to-onset, duration, and potential for recovery from the illness or injury, as well as the extent to which this health threat would shorten their expected lifespan. Each illness profile is randomly assigned a disease name, subject to a few exclusions for plausibility (e.g. no recovery from diabetes or Alzheimer's disease) ${ }^{9}$

For all disease risks (i.e. except for traffic accidents) each program reduces the risk of disease incidence via a diagnostic pin-prick blood test administered once per year by the individual's doctor. The test would indicate whether the individual is at risk of developing the illness in question. If so, the individual would be prescribed medication and/or lifestyle changes to reduce the chance of suffering the illness profile in question. ${ }^{10}$ Each risk reduction program is characterized specifically by a reduction in the probability of illness, and the associated cost of the program (in both annual terms and as monthly payments).

The final section of the survey consists of debriefing questions. Some of these are posed directly after each choice scenario. Another question asks about the respondent's confidence that diagnosis and treatment by his/her current health care provider would be both timely and of high quality. Debriefing questions also include assessments of scenario "buy-in," such as whether the individual believes they would personally benefit from the risk reduction program, and the number of years

\footnotetext{
${ }^{8}$ One complete version of the randomized survey instrument is archived in the supporting material for Cameron and DeShazo (2009), under Appendix A - Survey Design \& Development.

${ }^{9}$ The range of possible configurations for illness profiles is defined by the individual's age and gender. In other work, we have found that the disease labels (regardless of the underlying illness profile) do affect individual preferences to avoid adverse health states. These differences are addressed in Cameron et al. (2008). However, the randomization of disease labels across illness profiles ensures that our point estimates remain unbiased when we do not control for these differences. Any variation induced by subjective beliefs about specific disease names would be essentially orthogonal to the illness profiles considered in each scenario.

${ }^{10}$ For traffic accident scenarios, the program was described as car equipment such as new airbags, braking systems, and impact reduction technologies which could be retrofitted to existing vehicles, or included as an option on new vehicle purchases, with capital costs amortized into monthly payments.
} 


\section{Choose the program that reduces the illness that you most want to avoid. But think carefully about whether the costs are too high for you. If both programs are too expensive, then choose Neither Program.}

\section{If you choose "neither program", remember that you could die early from} a number of causes, including the ones described below.

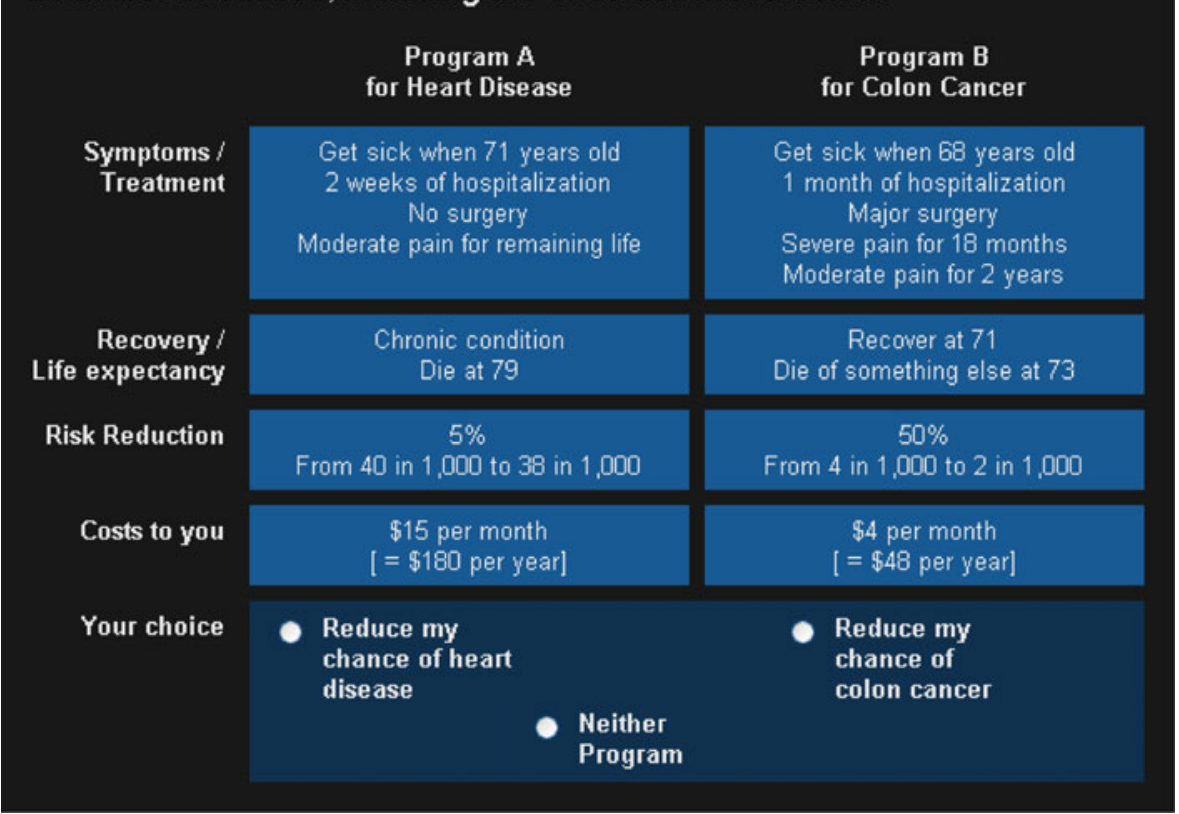

Fig. 1 One randomization of a conjoint choice set (See online Appendix A to Cameron and DeShazo (2009) for one version of the complete survey)

into the future when they think they would "begin to value highly the risk reduction benefits of each program" (which we interpret as the latency of the health threat). For Canadian respondents, information is solicited about whether the individual has previously sought care outside of their provincial health plan, since the health programs used in the choice scenarios are described as extra-ordinary care which would not be covered under their provincial health plan. ${ }^{11}$

The survey was administered to 2,439 respondents from the United States and 1,109 Canadians. ${ }^{12}$ Certain Canadian and U.S. respondents were excluded for three main reasons. First, if the respondent did not correctly answer the risk comprehension question, he or she was excluded from the analysis. Second, if the

\footnotetext{
${ }^{11}$ Through debriefing questions following each stated choice, respondents who said they would not choose either offered program had the option to indicate that this was because their provincial health plan should cover those tests.

${ }^{12}$ The response rate for the U.S. survey was 79\% (out of 3,000 initially solicited). The Canadian survey was administered over the internet by Ipsos Reid. Our budget did not permit for a separate survey instrument in French. Distinctions between WTP amounts in the French- and English-speaking populations of Canada may be important, but we are not able to address that question in this study.
} 
respondent rejected both programs in a particular choice scenario solely because they did not believe the program would work (rather than for "economic" reasons), the respondent's choice under that scenario was dropped from the analysis. Finally, randomization of illness profiles inadvertently resulted in a small number of implausible health profiles (about 1\%), and these were dropped to preclude any biases stemming from how they might have been interpreted. ${ }^{13}$

Although the Canadian survey was administered to the exclusively computerusing Ipsos-Reid consumer panel, the sample is similar to the English-speaking Canadian population on several observable dimensions. Table 1 presents a comparison of the Canadian and U.S. samples with their respective populations. Particularly with respect to the age distribution, the Canadian sample closely mirrors the corresponding Canadian population. Although the Canadian sample has fewer elderly ( $2 \%$ compared to $8 \%$ in the population), this is expected for a survey administered over the internet. The income distribution for the sample is skewed towards lower incomes compared to the population as a whole. The sample has a greater proportion of females to males, and a slightly greater proportion of the sample is married. Finally, although there are fewer nonwhites in the sample, the educational attainment (those earning a college degree or more) is similar between the sample and the Canadian population. These differences can be relevant because one needs to allow for the possibility of systematic variation in WTP across observable characteristics, so that differences in the types of people in the sample are not interpreted instead as differences in preferences, for similar types of individuals.

\section{Differential patterns in health beliefs and different health care systems}

Descriptive statistics presented in Table 2 show differences between the Canadian and U.S. samples in subjective health risks, confidence in the timeliness and quality of health care in the event of a major illness or injury, experience with going out-ofplan for health care (for Canadians only), and attitudes about certain health-related behaviors. Aggregating across all types of health threats addressed in the survey's choice sets, and across all ages, Canadian respondents perceive themselves to be more at high risk from the types of health threats being considered in this study. Disaggregating by type of health threat, the distributions of subjective risks remain fairly similar, although Canadians are somewhat more likely to rate their risks as high, and somewhat less likely to rate their risks as low.

Overall, Canadians believe there is somewhat less room to improve their health habits by seeing a doctor more regularly, but noticeably more respondents in Canada acknowledge that there is much room to improve their health by quitting smoking.

\footnotetext{
${ }^{13}$ This screening results in the exclusion of 1,236 choices from the U.S. sample and 1,040 choices from the Canadian sample due to risk comprehension failure; 2,236 choices from the U.S. sample and 393 choices from the Canadian sample due to scenario rejection; and 332 choices from the U.S. sample and 81 choices from the Canadian sample due to the unforeseen randomization error.
} 
Table 1 Demographic statistics by population and sample - Canada and U.S.

\begin{tabular}{|c|c|c|c|c|}
\hline & \multicolumn{2}{|l|}{ Canada } & \multicolumn{2}{|l|}{ U.S. } \\
\hline & Population & Sample & Population & Sample \\
\hline \multicolumn{5}{|l|}{ Age (years) } \\
\hline $25-44$ & $45 \%$ & $45 \%$ & $47 \%$ & $40 \%$ \\
\hline $45-64$ & 36 & 41 & 34 & 39 \\
\hline $65-74$ & 11 & 12 & 10 & 14 \\
\hline $75+$ & 8 & 2 & 9 & 7 \\
\hline \multicolumn{5}{|l|}{ Gender } \\
\hline Male & 50 & 41 & 49 & 49 \\
\hline Female & 50 & 59 & 51 & 51 \\
\hline \multicolumn{5}{|l|}{ Race } \\
\hline White & 87 & 96 & 77 & 80 \\
\hline Nonwhite & 13 & 4 & 23 & 20 \\
\hline \multicolumn{5}{|l|}{ Marital Status } \\
\hline Married & 48 & 56 & 54 & 69 \\
\hline Non-married & 52 & 44 & 46 & 31 \\
\hline \multicolumn{5}{|l|}{ Education } \\
\hline High school or less & 56 & 58 & 69 & 70 \\
\hline College Degree + & 44 & 42 & 31 & 30 \\
\hline \multicolumn{5}{|l|}{ Income (U.S.\$1000) } \\
\hline $10-$ & 3 & 14 & 10 & 6 \\
\hline $10-25$ & 20 & 31 & 19 & 17 \\
\hline $25-45$ & 35 & 36 & 24 & 23 \\
\hline $45-65$ & 21 & 12 & 21 & 24 \\
\hline $65-100$ & 14 & 5 & 14 & 21 \\
\hline $125+$ & 7 & 2 & 12 & 9 \\
\hline
\end{tabular}

Source: Statistics Canada, U.S. Census Bureau, and survey data (after exclusions). Interpolation required for income brackets (equal weight given to $\$ 5000$ increments). Domestic partners in Canada counted as married

With respect to getting more exercise, however, respondents in the two countries rate their room to improve as essentially the same.

It may be important that while Canadians are somewhat less likely to say that they have much room to improve the regularity with which they see their doctor, they are generally less confident that their current health care provider will afford them timely and effective diagnosis and treatment. Compared to the U.S. health care system, the Canadian provincial health plans may afford easier access to general practice physicians for basic care, but less access to specialists. We note that only about sixteen percent of the Canadian subsample have gone outside their provincial health plan specifically to obtain diagnostic tests.

The differences in health-related attitudes and beliefs between Canadian and U.S. respondents tend to vary in interesting ways with the age of the individual. 


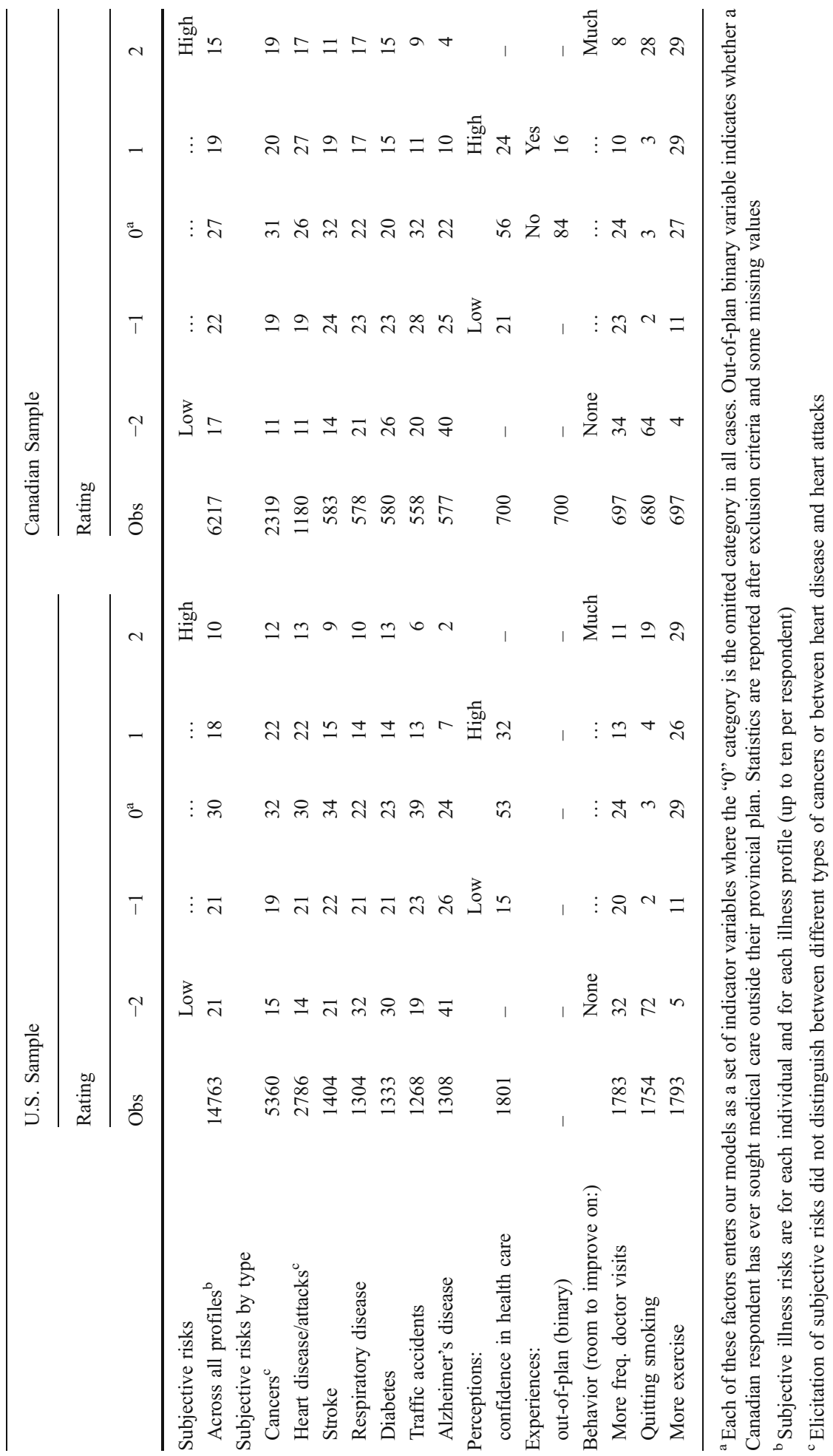


Appendix I provides numerous figures illustrating differences across countries, by age, in a variety of different measures. ${ }^{14}$ These graphs greatly condense the available information on ratings. They report age-wise means and intervals defined by plus and minus two standard deviations, where the standard deviations are adjusted to reflect sample size in the age group in question. ${ }^{15}$ In each figure, the triple of solid lines applies to the U.S. sample and the triple of dashed lines applies to the Canadian sample. As a caveat, these summary statistics treat the ordinal ratings as cardinal, so these graphs should be considered merely as a crude way to examine apparent variations by age level in the data.

The figures in Appendix I reveal differences in subjectively reported risks of suffering from all seven categories of health risks addressed in our study, as well as differences in subjectively reported room for improvement in seven types of personal health-related behaviors. Perceived risk from Alzheimer's disease and diabetes is generally higher for younger (and lower for older) Canadian respondents compared to respondents from the U.S. Perceived risk of acquiring one of five cancers (prostate, breast, colon, lung or skin) is somewhat lower for Canadian respondents over forty. For the risk of heart disease, younger and middle-aged Canadians reported higher subjective risks, while older Canadians (75 years and up) reported lower subjective risks (although this may reflect self-selection into the possibly healthier older internet-using sample in Canada). Canadian respondents reported substantially higher risks of acquiring respiratory disease for nearly all age groups, with the differential inverting only for those 75 and older (with the same caveat about the older Canadian sample). A similar pattern is seen for risk of strokes, while little difference is seen in perceived risk of traffic accidents up until the age of retirement, whereupon Canadians generally begin to report lower risks. Again, this could reflect selection biases in the older internet sample in Canada.

Compared to U.S. respondents, Canadian respondents report similar abilities to improve lifestyle habits with respect to losing weight and eating a healthier diet, but they report generally less opportunity at all ages to use a seat belt more, or see a doctor more regularly. Respondents from both samples report room to improve their health by quitting smoking, but Canadian respondents younger than sixty report more room than those in the U.S. sample. Younger Canadian respondents reported less opportunity to reduce alcohol consumption, with the relationship reversing at about age sixty, at which point older Canadians report considerably more opportunity to cut back on alcohol consumption.

The disease-specific age profiles reveal some degree of correlation between subjective beliefs about health risks and associated health habits. The higher perception of risk for diabetes and heart disease among Canadian respondents is correlated with a greater propensity to perceive room to reduce health risks by exercising more. Similarly, the higher reported risk among Canadians for respiratory disease is correlated with reports of room to improve health by quitting smoking. However, this correlation may simply mean that Canadians who report more room to improve their health by quitting smoking or by exercising more may translate these

\footnotetext{
${ }^{14}$ All appendices are available online at http://pages.uoregon.edu/cameron/JRU/CDS_Appendices.pdf.

${ }^{15}$ To enhance the main trends, these three age-wise statistics are presented as twenty-year moving averages.
} 
behavioral changes as substitutes for the diagnostic testing and treatment programs considered in the survey, for which they are therefore less willing to pay. Alternatively, however, the risk reduction programs offered in our stated choice scenarios may be seen as complements to these other health enhancement activities.

Finally, there are marked differences in confidence about diagnosis and treatment of major health problems across the two systems. Canadian respondents are generally less confident in the timeliness and quality of diagnosis and treatment until about age seventy, but beyond this age, there is less difference in the perceived efficacy of care. This may reflect the fact that U.S. seniors are covered by Medicare, which is more like the Canadian provincial health plans. Regarding experience with going outside of their provincial health plan for medical services, Canadian respondents have, on average, gone outside of their provincial plan for about one in five of the particular services listed in the survey question on this topic. ${ }^{16}$ However, as mentioned, only about sixteen percent of the Canadian sample has gone outside of their health plan specifically for diagnostic testing (analogous to the risk reduction program used to elicit willingness to pay information in the survey's stated choice scenarios).

\section{Demand for health risk reductions: structural utility-theoretic model}

The standard measure of mortality risk reduction benefits in the literature has been the Value of a Statistical Life (VSL). This statistic measures the marginal rate of substitution between mortality risk and income or wealth. It is common to estimate wage-risk or wealth-risk tradeoffs (Viscusi (1993)) by assuming that the individual considers just a single health threat, for which the risk is reduced by a small amount in the current period (Dreze (1962); Jones-Lee (1974)). The U.S. Environmental Protection Agency uses a one-size-fits-all VSL estimate of roughly \$6-7 million. Chestnut and De Civita (2009) provide a comprehensive review of published and unpublished Canadian estimates of the value of mortality risk changes of different types. In Canada, the figure has ranged from about $\$ 6.2$ to $\$ 9.9$ million.

It has been common in both the revealed preference (RP) and stated preference (SP) literatures on the valuation of mortality risk reductions to point out the limitations of a one-size-fits-all measure. ${ }^{17}$ As an alternative to the standard VSL measure, Cameron and DeShazo (2009) build a utility-theoretic model to produce estimates for individuals' willingness to swap other goods and services for microrisk reductions (i.e. risk reductions of size $10^{-6}$ ) for a variety of health threats. This willingness to pay for a microrisk reduction $\left(W T P_{\mu r}\right)$ measure allows for different valuations of health risk reductions across a variety of health states that make up a future "illness profile" (including a pre-illness current health state, illness-years, post-illness recovered/remission years, and lost life-years). By allowing marginal

\footnotetext{
${ }^{16}$ In addition to diagnostic tests, these medical services included physical exams, flu shots, major surgery, cosmetic surgery, immunizations for children or for travel, and "other."

${ }^{17}$ Baker et al. (2008) consider the conditions on the underlying social welfare function that would be necessary to justify the application of a single VSL estimate. They also address whether discounts or premia might be applied to take account of age or vulnerability of the population exposed to the risk. Sunstein (2004) raises the issue in the legal literature that VSL estimates should vary across individuals.
} 
utilities to vary across the different phases of an entire illness profile, the model integrates health states that have previously been valued in separate models or separate studies. It also permits us to recognize that "sudden death in the current period" is not the typical illness profile for most environmentally induced illnesses. Most such deaths are preceded by a period of pre-mortality morbidity that may have a substantial effect on individuals' willingness to pay to reduce their risk of suffering from such a health threat.

Starting from this more-general concept of WTP for microrisk reductions in the chance of suffering from arbitrarily specified illness profiles, it is possible to extract a special case that is close to the more-conventional VSL measure (which relates specifically to reducing the risk of sudden death in the current period). However, the new construct readily allows for other illness profiles which involve latency periods and protracted periods of pre-mortality morbidity (illness-years). It depends fundamentally upon the individual's current age and income. Our measure is also based fundamentally (if non-linearly) upon discounted years in each health state, although it is still possible to solve for an analog to the "value of a statistical lifeyear" (VSLY) by dividing an analog to the conventional VSL by discounted remaining life expectancy. ${ }^{18}$

The utility-theoretic choice model in this paper is based upon a specification described in detail in Cameron and DeShazo (2009) and the appendices to that paper, but we offer a brief outline of the basic framework of the model in this paper. We denote the two risk reduction programs in each choice set as A and B, and the status quo alternative for "neither program" as N. Each program reduces the risk of facing a specified illness profile, but involves a specified annual cost. The program cost is assumed to apply only during pre-illness-years and recovered years, so the individual would not pay for the program while sick (or dead) if he or she were to fall victim to the illness or injury. An illness profile is a sequence of future health states that includes a mutually exclusive and exhaustive combination of pre-illness-years, sick years, post-illness recovered/remission years (if any) and lost life-years (if death is premature). Only single spells of any given illness are described. Respondents are assumed to maximize utility subject to their budget constraint, and thus to choose the alternative that gives them the highest level of utility.

For simplicity, consider just the pair-wise choice between program A and N. ${ }^{19} \mathrm{We}$ assume that the utility of an individual, $i$, at time, $t$, depends upon net income in that period, $Y_{i t}$ minus the cost of any program, $c_{i t}$, as well as the health state they experience in that period. In any given period, the individual will be in one of the four possible health states, which are captured using four indicator variables: $1\left(\right.$ pre $\left._{i t}\right)$ for pre-illness-years, $1\left(i l_{i t}\right)$ for illness-years, $1\left(r c v_{i t}\right)$ for post-illness recovered/ remission years, and $1\left(l y l_{i t}\right)$ for life-years lost. We can write the individual's indirect utility function in each time period, $\mathrm{t}$, as:

$$
V_{i t}=f\left(Y_{i t}-c_{i t}\right)+\alpha_{0} 1\left(\text { pre }_{i t}\right)+\alpha_{1} 1\left(i l l_{i t}\right)+\alpha_{2} 1\left(r c v_{i t}\right)+\alpha_{3} 1\left(l y l_{i t}\right)+\eta_{i t}
$$

\footnotetext{
${ }_{18}$ Sunstein (2003) addresses the question of whether benefit-cost analysis should employ the value of statistical lives, or statistical life-years. VSLY calculations are explained in Moore and Viscusi (1988), Viscusi and Hersch (2008), and Aldy and Viscusi (2008).

19 The three-way choice between two programs and neither program is analogous.
} 
There is uncertainty about whether the individual will actually fall sick from the disease, so we model each choice as depending upon expected indirect utility, with the expectation taken across the sick $(\mathrm{S})$ and healthy $(\mathrm{H})$ outcomes. Participation in program A vs. $\mathrm{N}$ is described as altering the probability of getting sick from $\pi_{i}^{N S}$ to $\pi_{i}^{A S}$ (where we define this risk change as $\Delta \pi_{i}^{A S}=\pi_{i}^{A S}-\pi_{i}^{N S}$ ). Furthermore, each illness profile extends through the remainder of the individual's life expectancy, so we discount future time periods using a constant discount rate $r$ and discount factor $\delta^{t}=(1+r)^{-t}$ to get the present discounted value $(P D V)$ of expected indirect utility for individual $i$. The individual is assumed to choose program A over $\mathrm{N}$ if his or her discounted expected utility is greater under A:

$$
P D V\left(\pi_{i}^{A S} V_{i}^{A S}+\left(1-\pi_{i}^{A S}\right) V_{i}^{A H}\right)-P D V\left(\pi_{i}^{N S} V_{i}^{N S}+\left(1-\pi_{i}^{N S}\right) V_{i}^{N H}\right)>0
$$

The present discounted number of years making up the remainder of the individual's nominal life expectancy, $T_{i}$, is given by $p d v c_{i}^{A}=\sum_{t=1}^{T_{i}} \delta^{t}$. Discounted time periods spent in the pre-illness state, the recovered/remission state, and as lost life-years from $t=1$ to $t=T_{i}$ are given by:

$$
\begin{gathered}
p d v e_{i}^{A}=\sum \delta^{t} 1\left(p r e_{i t}^{A}\right), p d v i_{i}^{A}=\sum \delta^{t} 1\left(i l l_{i t}^{A}\right), \\
p d v r_{i}^{A}=\sum \delta^{t} 1\left(r c v_{i t}^{A}\right), \text { and } p d v l_{i}^{A}=\sum \delta^{t} 1\left(l y l_{i t}^{A}\right) .
\end{gathered}
$$

The different health states exhaust the individual's nominal life expectancy, so $p d v e_{i}^{A}+p d v i_{i}^{A}+p d v r_{i}^{A}+p d v l_{i}^{A}=p d v c_{i}^{A}$. Finally, to accommodate the assumption that each individual expects to pay program costs only during the pre-illness or recovered post-illness periods, $p d v p_{i}^{A}=p d v e_{i}^{A}+p d v r_{i}^{A}$ is defined as the present discounted time over which payments must be made.

To further simplify notation, let:

$$
\begin{aligned}
& \operatorname{cterm}_{i}^{A}=\left(1-\pi_{i}^{A S}\right) p d v c_{i}^{A}+\pi_{i}^{A S} p d v p_{i}^{A} \\
& \operatorname{yterm}_{i}^{A}=p d v c_{i}^{A}-\left(\pi_{i}^{A S} p d v i_{i}^{A}+\pi_{i}^{N S} p d v l_{i}^{A}\right) \\
& \operatorname{pterm}_{i}^{A}=\Delta \pi_{i}^{A S}\left[\alpha_{1} p d v i_{i}^{A}+\alpha_{2} p d v r_{i}^{A}+\alpha_{3} p d v l_{i}^{A}\right]
\end{aligned}
$$

The complexity of cterm $_{i}^{A}$ and term $_{i}^{A}$ merely reflect the fact that net income over the future will depend on whether the individual will be sick or dead, with probabilities depending upon the chance of getting sick, with and without the testing program. The abbreviation pterm $_{i}^{A}$ is thus not the only term in the model that reflects the illness profile in question.

Then the expected utility-difference that drives the individual's choice between programs $\mathrm{A}$ and $\mathrm{N}$ can then be defined as follows:

$$
\Delta P D V\left(E_{S, H}\left[V_{i}\right]\right)=\left\{f\left(Y_{i}-c_{i}^{A}\right) \text { cterm }_{i}^{A}-f\left(Y_{i}\right) \text { yterm }_{i}^{A}\right\}+\text { pterm }_{i}^{A}+\varepsilon_{i}^{A}
$$

The option price, in the sense of Graham (1981), is the common maximum certain payment that makes an individual indifferent between paying for the program and having the risk reduction, or not paying for the program and not having the risk 
reduction. Here, we solve for the common payment which makes the difference in discounted expected utility between program $\mathrm{A}$ and $\mathrm{N}$ equal to zero:

$$
\widehat{c}_{i}^{A}=Y_{i}-\left(\frac{\beta \sqrt{Y_{i}} \text { yterm }_{i}^{A}-\text { pterm }_{i}^{A}-\varepsilon_{i}^{A}}{\beta \text { cterm }_{i}^{A}}\right)^{2}
$$

where $f(Y)=\beta \sqrt{Y_{i}}$ has been selected as the best-fitting simple functional form. ${ }^{20}$ The square root form introduces some necessary curvature with respect to net income, yet preserves the monotonic form. The expected present value of this common certain payment can then be calculated for the individual's remaining lifetime and can be written as:

$$
E_{S, H}\left[P V\left(\widehat{c}_{i}^{A}\right)\right]=\operatorname{cterm}_{i}^{A}\left[\widehat{c}_{i}^{A}\right]
$$

We can divide $E_{S, H}\left[P V\left(\hat{c}_{i}^{A}\right)\right]$ by the size of the risk reduction, $\left|\Delta \pi_{i}^{A S}\right|$ to get a construct analogous to the commonly calculated Value of a Statistical Life when the illness profile consists simply of sudden death in the current period. Scaling this amount to an individual risk change of just 0.000001 produces an estimate of willingness to pay for a microrisk reduction $\left(W T P_{\mu r}\right)$, typically amounting to some small number of dollars for a 0.000001 risk reduction:

$$
W T P_{\mu r}=E_{S, H}\left[P V\left(\widehat{c}_{i}^{A}\right)\right] /\left|\Delta \pi_{i}^{A}\right| \times 10^{-6}
$$

This $W P_{\mu r}$ is a marginal rate of substitution (the ratio of the marginal utility of the sequence of health states to the marginal utility of income) scaled arbitrarily to a small individual risk reduction that is more on the order of the individual risk reductions offered by many environmental policies. ${ }^{21}$

For an illness profile consisting of sudden death in the current period (so that $p d v l_{i}^{A}=p d v c_{i}^{A}$ ), we can divide this willingness to pay by the individual's discounted remaining number of life-years to yield a construct analogous to the VSLY (value of a statistical life-year) equal to $W T P_{\mu r} / p d v l_{i}^{A}$.

The marginal (dis)utility of an adverse illness profile is in the numerator of the $W T P_{\mu r}$, so an increase in the marginal disutility of any component of an illness/injury profile of health states-illness-years, recovered/remission years, and lost life-years - will increase the $W T P_{\mu r}$. Since the marginal utility of income is in the denominator, an increase in the marginal utility of income will decrease the $W T P_{\mu r}$.

To illustrate the implications of our fitted model for willingness to pay for health risk reductions, it is necessary to choose a particular type of individual and a particular type of illness profile. In this paper, we will focus on the illness profile that is assumed in most wage-risk VSL studies - sudden death in the current period. However, the $W_{T P}$ framework does allow one to simulate willingness to pay to reduce the risk of a vast array of different illness profiles: with or without latency, with different lengths of illness, with or without recovery, and with or without any decrease in life expectancy.

\footnotetext{
${ }^{20}$ Suggested by a line-search across possible Box-Cox transformation parameters.

${ }^{21}$ Based on the arguments in Cameron (2010), we make an effort here to focus on WTP for microrisk reductions, rather than the VSL.
} 
To build a distribution of $W T P_{\mu r}$ values for a particular type of health risk for a particular population, more-general simulations would be used. It would be necessary to specify the distribution of illness profiles that is likely to result from the health threat, the magnitudes of the risk reductions, and the types of individuals (ages, genders, incomes) who would be affected by these risk reductions. WTP $P_{\mu r}$ estimates could then be simulated for each of a large number of random draws from the distributions of risks (possible illness profiles) and affected individuals to produce a distribution of $W T P_{\mu r}$ estimates for the policy in question. In this paper, however, we will simply illustrate the disparities in predicted willingness to pay for a standardized illness profile, emphasizing the interpersonal and international differences in $W T P_{\mu r}$ to reduce the risk of this standard profile.

\section{Empirical analysis}

In Table 3, we begin with a simple four-parameter indirect utility-difference specification (Model 1) which allows for differences between U.S. and Canadian preferences by interacting each baseline variable with an indicator for the Canadian subsample. Thus the first column of estimates in each pair gives the baseline coefficient for the U.S. sample and the second column gives the differential in the coefficient for the Canadian sample. Cameron and DeShazo (2009) have shown that marginal utilities from discounted time in each health state depend upon the duration of that state so we use a shifted log functional form to allow for diminishing marginal (dis)utilities for increased lengths of time in each adverse health state. This basic model thus includes a net income term (net of program cost, if a risk reduction program is selected) along with terms for illness-years, $\Delta \pi_{i}^{A S} \log \left(p d v i_{i}^{A}+1\right)$, recovered/remission years, $\Delta \pi_{i}^{A S} \log \left(p d v r_{i}^{A}+1\right)$, and lost life-years $\Delta \pi_{i}^{A S} \log \left(p d v l_{i}^{A}+1\right)$.

Assuming identical error dispersions, permitting the data to be pooled, the results for Model 1 suggest a higher marginal utility of income and considerably less disutility from lost life-years for Canadians. As expected, for individuals from both countries, the marginal utility of net income (i.e. other consumption) is positive (but diminishing, given the square-root functional form). The marginal utilities associated with each of the three adverse future health states are negative (and diminishing, given the $\log$ functional form). ${ }^{22}$

Model 2 in Table 3 presents the results of a utility specification with ten parameters which allows for systematic variation by age in the marginal (dis)utility from lost life-years. We adopt a model similar to that specified in Cameron and DeShazo (2009), which is the parsimonious version including only the statistically

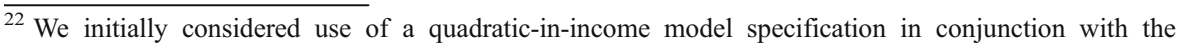
shifted-log functional form for health states. Parameter estimates from the quadratic-in-income model are consistent with all expectations: positive and decreasing marginal utilities of income, which are positive over the range of incomes included in the sample. However, moving to a square root functional form for preferences over income had two advantages: 1) it prevents the marginal utility of income from ever straying into negative territory (especially when all covariates are included), and 2) it produces superior $\log$-likelihood statistics. We therefore retain this restriction throughout their analysis.
} 


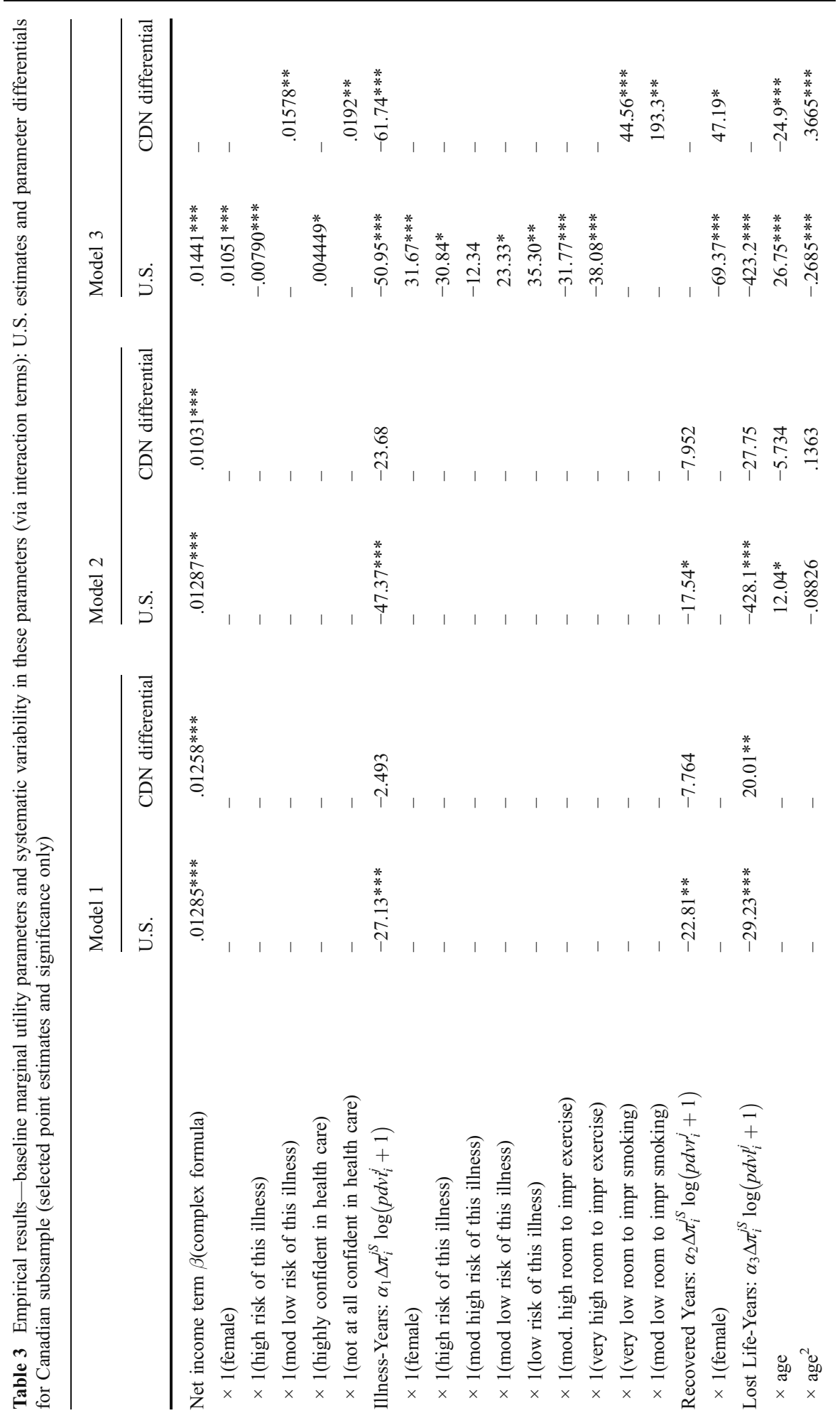




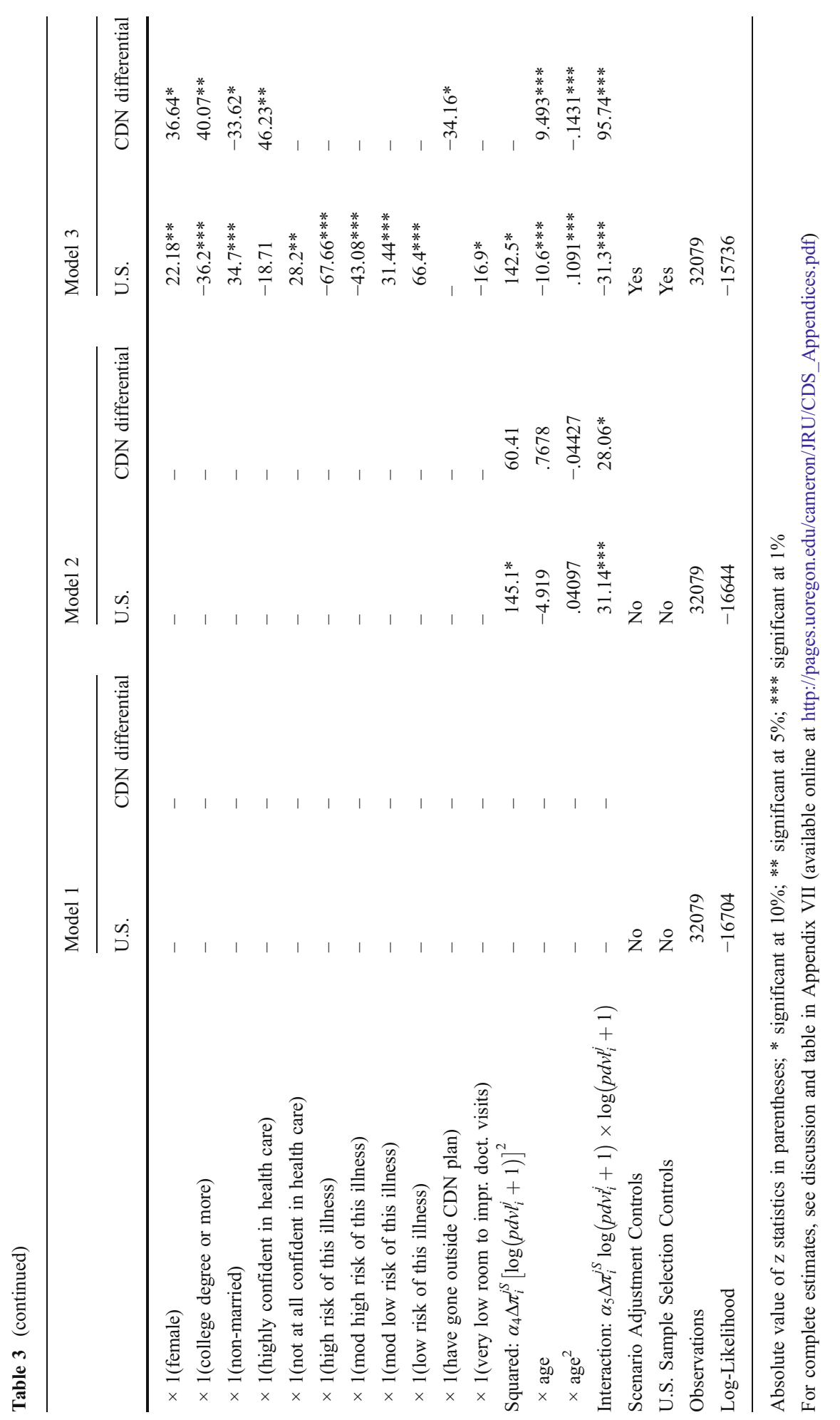


significant terms in a fully translog model (including all squares and pairwise interaction terms for the three $\log$ terms). The construct called pterm $_{i}^{A}$ in (3) becomes:

$$
\Delta \pi_{i}^{A S}\left[\begin{array}{l}
\alpha_{1} \log \left(p d v i_{i}^{A}+1\right)+\alpha_{2} \log \left(p d v r_{i}^{A}+1\right)+\alpha_{3} \log \left(p d v l_{i}^{A}+1\right) \\
+\alpha_{4}\left\{\log \left(p d v l_{i}^{A}+1\right)\right\}^{2}+\alpha_{5}\left\{\log \left(p d v i_{i}^{A}+1\right) \log \left(p d v l_{i}^{A}+1\right)\right\}
\end{array}\right]
$$

To accommodate age, the $\alpha$ coefficients are allowed to differ systematically with the respondent's current age wherever this generalization is warranted by the data. This leads to a model where $\alpha_{3}=\alpha_{30}+\alpha_{31} a g e_{i}+\alpha_{31} a g e_{i}^{2}$, and analogously for $\alpha_{4}{ }^{23}$

Inclusion of age heterogeneity and more flexible functional form assumptions certainly improves the explanatory power of our model. However, the statistically significant difference in Model 1 in the disutility of discounted lost life-years between Canada and the U.S. disappears in Model 2. A number of important attitudinal differences are not reflected in this model, however. For example, Canadian and U.S. individuals have different age profiles for attitudes about smoking behavior, and Canadians perceive that they have less room to improve their health habits by seeing a doctor more regularly (among other attitudinal differences mentioned above). These differences in the two samples could be conflated with differences in preferences across people who might otherwise seem very similar in terms of income and age. Since the Canadian and U.S. samples also differ somewhat along a number of demographic dimensions (such as marital status, education, and gender), it is reasonable to expect that controlling for these differences may matter.

Additionally, as addressed in Cameron et al. (2007), our survey was designed to elicit useful information about preferences over the stated health scenarios through tutorials and careful explanations about how the choice tasks should be approached. However, the potential for respondents to subjectively adjust the choice scenarios to more closely reflect their own situation was assessed through follow-up questions. A share of our sample appears to either over- or under-estimate the illness latency, and/ or report a different estimate of their own life expectancy than was specified in their personal (age- and gender-indexed) version of the survey. If these extra-scenario beliefs factor into the respondent's selection of a most-preferred alternative, then the effect of these various scenario adjustments could yield biases in the most important parameter estimates. Our final model therefore includes a number of incidental variables to control for possible "scenario adjustment" by respondents. These are reported in detail along with the expanded version of our results provided in Appendix VII (available online at http://pages.uoregon.edu/cameron/JRU/ CDS_Appendices.pdf).

Model 3 in Table 3 presents estimates for a specification with preferences that are heterogenous along more dimensions than just age, where richer systematically varying parameters replace the scalar marginal utilities of income and discounted

\footnotetext{
${ }^{23}$ Inclusion of the squared lost life-years term enhances the flexibility of the specification. The interaction term between illness-years and lost life-years allows the marginal disutility from a discounted lost life-year to depend upon the number of preceding sick-years. It is possible that the value of an incremental life-year is diminished by a preceding serious illness (with the prospect of pain and disability and a loss of selfsufficiency). An illness that is sufficiently severe, long-lasting, and terminal may indeed be a fate worse than death.
} 
future health states $\left(\beta\right.$ and $\alpha_{1}$ through $\left.\alpha_{5}\right){ }^{24}$ The key results for Model 3 are the marginal utility parameters from a parsimonious specification where additional socio-demographic and attitudinal covariates are interacted with the net income terms and our illness-state variables. As for Models 1 and 2, the second column of coefficients for Model 3 gives the coefficient differentials on interaction terms involving the Canadian-sample indicator variable. The estimates in the final column in Table 3 clearly show that there are differences between Canadian and U.S. preferences with respect to the attributes of the illness profiles.

Before reviewing the estimates for Model 3 and their implications for $W T P_{\mu r}$, we emphasize the endogeneity of the subjective risk variables, people's health habits, their confidence in their current health care, and, for Canadians, whether they have ever gone outside their provincial health plan for care. The estimated coefficients on interaction terms involving these variables thus imply only that a relationship exists, not that causality has been established. Coefficients with plausible signs, however, imply a degree of "theoretical construct validity" for our estimates, in that variations in WTP for health risk reductions are consistent with intuition.

In Table 3, recall that the coefficients on variables which are interacted with the net income term reveal the sign of the effect of each variable on the $\beta$ parameter, and hence on the marginal utility of income. This marginal utility appears in the denominator of the $W T P_{\mu r}$ formula, so anything that makes the marginal utility of income larger will tend to reduce $W T P_{\mu r}$ for a reduction in the risk. In contrast, variables which shift any of the $\alpha$ parameters affect the numerator of the $W T P_{\mu r}$ formula. In the following sections, we will discuss the effects of heterogeneity, across individuals and between the two countries, by category of variable.

\subsection{Effects of subjective risks}

Subjective risks of illness affect the marginal utility of income (and thus $W T P_{\mu r}$ ) via the $\beta$ parameter. These subjective risks appear to have different influences for Canadians and U.S. respondents. ${ }^{25}$ A high subjective risk of the illness profile in question results in a lower marginal utility of income for all respondents (and hence contributes to a higher $W T P_{\mu r}$ to reduce the risk of that illness). Respondents in the U.S. who report moderately low subjective risks for the illness in question have a $W T P_{\mu r}$ that is not distinguishable from that for individuals who have either moderate or very low subjective risks. However, Canadians who report a moderately low subjective risk of the illness in question can be discerned to have a systematically higher marginal utility of income and thus a lower $W T P_{\mu r}$ to reduce the risk of that illness.

Subjective risks also influence willingness to pay for health risk reductions via the $\alpha_{1}$ and $\alpha_{3}$ parameters on the illness-years and lost life-years terms, but these effects

\footnotetext{
${ }^{24}$ The complete sets of estimates for all three models in Table 3, including a variety of incidental parameters, are provided in Appendix VII.

${ }^{25}$ Our analysis maintains the hypothesis that the error variances are the same for both the U.S. and Canadian samples. Since the survey instruments are virtually identical, this may be a reasonable assumption. If we were to find that the U.S. and Canadian coefficients were proportional, of course, different error variances would be the first thing to suspect, but the parameters do not appear to be proportional. Relaxing the assumption of equal error variances would require specially designed maximum likelihood estimators, so we leave that issue for future work.
} 
seem to be similar in Canada and the U.S. For both health states, and for both countries, a high subjective risk for the illness in question increases the disutility associated with illness-years and lost life-years and thus increases the value attached to a reduction in the risk of suffering from that particular health threat. A perception of being at lower risk reduces the value. ${ }^{26}$

\subsection{Effects of confidence in effective and timely treatment}

Respondents in the U.S. who are "highly confident" that diagnosis and treatment by their current health care provider would be both timely and of high quality have a higher marginal utility of income, via the $\beta$ parameter, and thus have lower WTP to reduce the risk of any type of illness profile. These individuals may view the offered diagnostic programs as substitutes for their existing health care services. However, Canadians who are "not at all confident" in the timeliness and efficacy of their current health care also have a higher marginal utility of income and therefore a lower WTP to reduce their risk of any type of illness profile. There are no statistically significant effects of age on the marginal utility of income in our model. Thus the U.S. effect may reflect the influence of retirees with low current income but access to Medicare. In Canada, however, a lack of confidence in the health care system could be related to lower-income rural areas with limited access to physicians.

Via the $\alpha_{3}$ parameter, having confidence in the timeliness and quality of diagnosis and treatment has a positive effect on the value attached to avoiding early death for U.S. respondents, but it appears to reduce the value from avoided premature death for Canadians. For residents of both countries, a lack of confidence in the health care system seems to reduce the marginal value attached to reductions in lost life-years. This suggests that people may not wish to prolong their lives so much if they are not sure what quality-of-life will be offered by the health care they will be able to enjoy. For the U.S., greater confidence in the timeliness and quality of care may translate into higher willingness to pay for diagnostic tests that will help avoid lost life-years, but the effect is not statistically significant. For Canadians, however, greater confidence in timely and high-quality care seems to reduce the marginal value attached to lessening the risk of early death.

\subsection{Effects of respondent age}

Our results with respect to the effect of respondent age on preferences over lost lifeyears are particularly interesting. In general, age effects tend to be smaller in absolute value for Canadians, and relatively more pronounced for U.S. residents. Respondent age affects both the baseline marginal utility of lost life-years, $\alpha_{3}$, as well as the coefficient on the squared term in the shifted logarithm of discounted lost life-years, $\alpha_{4}$. Put simply, older individuals seem to value lost life-years less, with

\footnotetext{
${ }^{26}$ Van Houtven et al. (2008) offer a recent national survey that distinguishes between accident-related deaths and cancer deaths, noting the presence of a cancer premium. Different types of health threats may be more or less salient to different respondents, which may be due to different subjective risks of these different illnesses.
} 
the value of any individual lost life-year decreasing in the number of years lost overall. For Canadians, however, this age effect is almost (though not completely) offset by opposite signs on the shift coefficients, suggesting that at least for our sample, Canadians exhibit smaller age effects. However, due to the variety of ways in which age enters the model, simulations are necessary to illustrate the net effects of the eight statistically significant age coefficients in Model 3.

4.4 Other factors affecting the marginal utility of sick-years, recovered/remissionyears, and lost life-years

The $\alpha_{1}$ parameter on the term in discounted sick-years is expected to be negative, since prospective sick-years confer disutility. Canadians, in general, get more disutility from sick-years than do U.S. respondents, so they value avoided illnessyears considerably more than do individuals in the U.S. For both countries, however, higher subjective risks of disease amplify the marginal disutility of illness-years and increase $W T P_{\mu r}$ for the risk-reduction program. Females in both countries have lesser aversion than males to illness-years and are therefore willing to pay less, while respondents who admit that they could improve their health habits with more exercise derive greater disutility from illness and are willing to pay more for these diagnostic and treatment programs. They may view these programs as substitutes for better health habits. For Canadians, smoking status also appears to have a strong relationship to the marginal disutility of becoming sick. Those who report very little room to improve their health habits by quitting smoking have substantially smaller disutilities associated with illness-years. We assume that these people are nonsmokers or infrequent smokers (or smokers who do not believe that their health is adversely affected by smoking). These individuals are willing to pay less for the offered programs.

For the $\alpha_{2}$ parameter for both countries, males tend to assign little marginal value to reducing the number of recovered/remission years, while women from both countries (and the U.S. in particular) are willing to pay to avoid recovered/remission years. This provides an interesting contrast: for women, morbidity is apparently still expected to be present in the recovered/remission state following one of these major illnesses, whereas men appear to perceive recovered/remission years as a fully recovered state that provides a level of utility equivalent to their pre-illness state. Men appear to attach value only to avoided illness-years and avoided lost life-years.

The sociodemographic and attitudinal variation in the $\alpha_{3}$ parameter shows that females appear to derive less disutility from lost life-years than do males, and even more so in Canada than in the U.S. Combined with a higher marginal utility of net income for women, this will tend to reduce their $W T P_{\mu r}$ for mortality risk reductions. Having a college degree increases the marginal value attached to lost life-years, while being non-married reduces it; however, this effect is present only for U.S. respondents, with the point estimates on the Canadian interaction terms almost exactly offsetting the effect. For Canadians, having had some previous experience with going outside of their provincial health plan for diagnostic testing has a weakly significant and positive effect on the disutility of lost life-years, so that these individuals are willing to pay more for health risk reductions when the health threat involves premature death. Finally, individuals who feel they have little room to improve their 
health habits by seeing a doctor more regularly are more willing to pay to reduce their risks of lost life-years. These people may be more health-conscious in general.

Canadians and U.S. respondents exhibit strikingly different coefficients on the interaction term between illness-years and lost life-years. While U.S. respondents derive greater disutility from lost life-years after a longer period of illness, the opposite effect seems to be present in Canada. For Canadians, the disutility from lost life-years is reduced as the number of preceding illness-years increases. Thus, in Canada, it may be the case that a long period of illness may evolve into a "fate worse than death," whereas in the U.S., the average individual may want to prolong life no matter how bad an illness gets. ${ }^{27}$

\subsection{Implications}

Model 3 illustrates the importance of including a rich set of attitudinal and demographic controls when modeling differences in preferences across jurisdictions. When there are unequal relative frequencies for different types of respondents in the two countries, failure to control for individual heterogeneity could easily distort the coefficients on the interaction terms involving the indicator for the Canadian subsample. Table 1 reveals that Canada has a higher proportion of non-married individuals, and a higher proportion with a college degree or more (despite lower Canadian incomes). ${ }^{28}$ These sociodemographic variables have significant effects on the estimated magnitude of the marginal disutility of a lost life-year, but these effects also differ across countries.

\section{Simulation results}

Based upon our preferred specification (Model 3), we explore a number of simulations of the fitted distribution of WTP for a $10^{-6}$ reduction in the risk of sudden death. This is also known as a "microrisk reduction" $(\mu r)$ or, in this special case of an illness profile consisting of sudden death, as a "micromort"). We differentiate our fitted age profiles for Canadian and U.S. respondents, for males and females, for individuals with and without a college education, and for those who are married or not married. Additionally, for Canadian males, we simulate $W T P_{\mu r}$ for those with and without experience with out-of-plan diagnostic testing procedures. All dollar-denominated amounts in our study are converted to U.S. dollars (circa the first quarter of 2003). ${ }^{29}$

\footnotetext{
$\overline{{ }^{27} \text { If we allow the coefficient } \alpha_{5}}$ to vary with the respondent's level of confidence in their current health care, there is weak evidence (i.e. at only an $11 \%$ level of significance) that greater confidence may actually lessen the disutility associated with lost life-years for each additional year of prior morbidity. Thus the distinction between U.S. respondents and Canadians does not seem to be merely an artifact of Canadians' lesser confidence in their health care.

${ }^{28}$ However, the implicit value of the provincial health plans is not included in the Canadian income data. Differences in the proportion of non-whites in the self-reported data for the two countries appear to be unimportant. This variable had no robustly statistically significant effect on any of the utility parameters. ${ }^{29}$ We convert the value of a Canadian dollar into equivalent U.S. dollars, using the contemporaneous interbank exchange rate as of $12 / 01 / 02$, equal to $\$ 0.63902$. The Canadian sample was collected first, at the end of 2002. The U.S. sample was collected early in 2003, so we refer to all dollar amounts as "2003 US dollars."
} 
Our simulations are benchmarked for average sample income in the U.S. (roughly $\$ 42,000$ U.S.). We assume a discount rate of $5 \%$, and we focus on the illness profile consisting of sudden death in the current period (i.e. death with no latency and no prior illness) so that our model's predictions can be compared to standard VSL estimates. Fitted $W T P_{\mu r}$ based on Model 3 is calculated with subjective and attitudinal variables simulated at their baseline (i.e. omitted-category) values. These subjective and attitudinal variables include perceived risk of the illness or injury in question, room to improve health by increasing exercise, quitting smoking, and seeing a doctor more regularly, and confidence in diagnosis and treatment under Canadian or U.S. health systems. ${ }^{30}$

\section{$5.1 W_{\mu r}$ to reduce a risk of sudden death (by age of respondent)}

For each type of simulation, we vary age in five-year increments from 25 to 80 years to permit us to graph the implied age profile. In each case, we make 1,000 random draws from the asymptotically joint normal distribution of the maximum likelihood parameter estimates. This variability in parameter values, in combination with specified values for each of the explanatory variables which appear in the model, allow us to generate a "sampling distribution" for $W T P_{\mu r}$ that reflects the degree of precision in the estimated parameters.

Appendices II through VI (available online at http://pages.uoregon.edu/cameron/ JRU/CDS_Appendices.pdf) present graphs of the age profiles of our simulation results - broken out by gender, educational attainment, marital status, and out-of-plan experience. Individual figures show either (a.) the median (solid line) and 5th and 95th percentiles (dashed lines) for 1,000 draws from the estimated joint distribution of parameters calculated at each five-year age level between 25 and 80 years, or (b.) just the median simulated value, for each of several different types of individuals, permitting us to compare age profiles for $W T P_{\mu r}$ across the different groups.

The age profile of WTP for a microrisk reduction in the chance of sudden death is considerably different for the Canadian and U.S. samples. Canadians, regardless of gender, education, or marital status, have a flatter age profile of $W T P_{\mu r}$ to reduce risk of early death, with peak $W T P_{\mu r}$ realized at a substantially older age (around age 60 for Canadians compared to age 35-40 for individuals from the U.S.). In general, Canadians are willing to pay more at older ages, but U.S. respondents are willing to pay more at younger ages. Across the 1,000 sets of parameter draws, peak median $W T P_{\mu r}$ for Canadians males is only $\$ 8.71$ annually (at age 60 ), compared to $\$ 10.46$ for males from the U.S. (at age 35-40). Females have substantially lower $W T P_{\mu r}$ for sudden death regardless of country of residence: we find a peak median $W T P_{\mu r}$ of only $\$ 3.04$ for Canadian females (age 60), but \$5.72 for U.S. females (at age 35-40). These age profiles are shown in Fig. 2 for U.S. and Canadian males and females.

\footnotetext{
$\overline{{ }^{30} \text { It is essential to use } \text { cterm }_{i}^{j} \text { and }}$ yterm $_{i}^{j}$ to explain respondents' stated choices among the privately paid diagnostic testing programs used in our choice scenarios. For public policies to reduce risks, however, people may expect to keep paying the cost of the policy even if they get sick, and they may not consider the chance that premature mortality could free them from paying the cost of the policy but leave them with no other consumption either. For benefits transfer, it may thus be appropriate to assume $\operatorname{cterm}_{i}^{j}=y \operatorname{term}_{i}^{j}=p d v c_{i}^{j}$. Here, however, we simulate $W T P_{\mu r}$ using the forms in (3), with $\pi_{i}^{N S}$ and $\pi_{i}^{j S}$ arbitrarily set to .004 and .001 .
} 
med WTP for a 1/1,000,000 reduction in mortality risk

(sudden death, current period; income $=\$ 42 \mathrm{~K}, r=0.05$ )

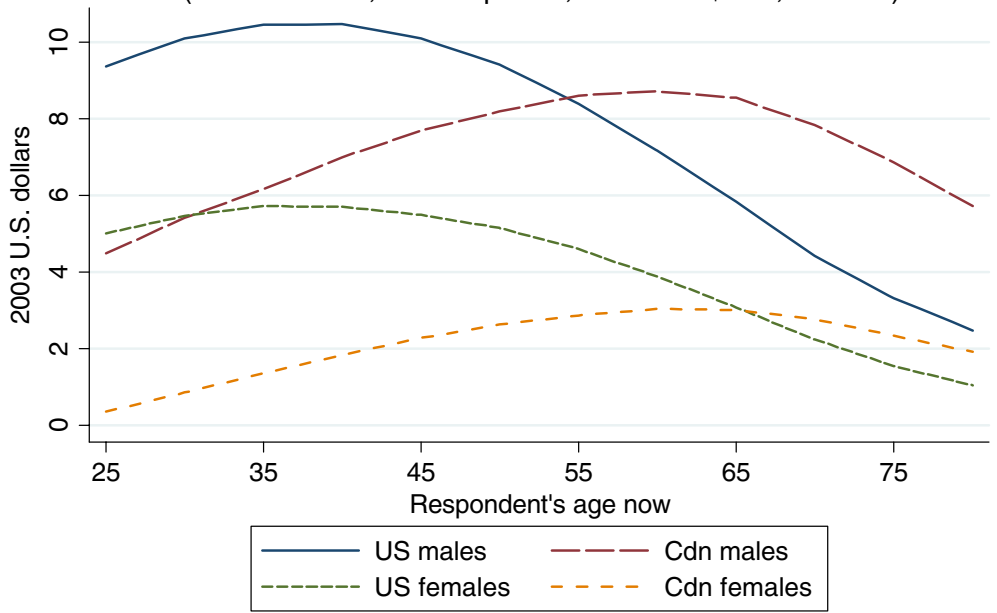

Fig. 2 Male and female age profiles for median WTP in the U.S. and Canada (see Appendix II for 5th and 95th percent intervals around each median. Appendices available online at http://pages.uoregon.edu/ cameron/JRU/CDS_Appendices.pdf)

\subsection{Comparisons to the literature on VSLS}

The illness profile in question is sudden death in the current period, so multiplication of these $W T P_{\mu r}$ amounts by one million will yield a number roughly comparable to standard estimates of the value of a statistical life (VSL). Several meta-analyses of VSL estimates in general have been conducted, including Mrozek and Taylor (2002), Viscusi and Aldy (2003), and Kochi et al. (2006), but we focus here on the literature on VSLS as a function of age. Aldy and Viscusi (2008) determine from cohortadjusted age-specific hedonic wage equations that workers' VSLs start at \$3.39 million at age eighteen, rise to a peak of $\$ 7.79$ million at age 46 , then decline again to $\$ 5.09$ million at age 62 , the highest age in their sample of workers.

Our general-population sample of U.S. respondents suggests $W T P_{\mu r}$ estimates corresponding to a VSL at age 25 of about $\$ 9.36$ million for males and about $\$ 5.01$ million for females. (The youngest respondents in our sample are 25 years old. We do not attempt any out-of-sample simulations for age eighteen, but our model suggests that VSL $s$ would be smaller at age eighteen than at age 25.) Values peak around age 35-40 at about $\$ 10.46$ million for males and $\$ 5.72$ million for females. Then they decline by age 65 to about $\$ 5.83$ million for males and $\$ 3.08$ million for females. Thus our general population male and female estimates appear to bracket the VSL estimates of Aldy and Viscusi (2008) at those ages where our estimates can be roughly compared. ${ }^{31}$

We certainly find noticeable differences between the U.S. and Canada. This contrasts with the results of Chestnut et al. (2009), where no statistically significant differences between the two countries are found.

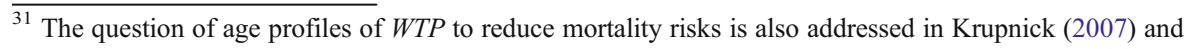
Aldy and Viscusi (2007). 


\subsection{Comparisons to the literature on VSLYS}

We have also calculated the corresponding age profiles of our analog to the value of a "statistical life-year" (VSLY). Our estimates for the average $W T P_{\mu r}$ per discounted lost life-year are shown in Fig. 3, with simulated confidence intervals provided in Appendix III. As in Aldy and Viscusi (2008), these profiles take an inverted U-shape. In the U.S., the simulated medians of these average values peak around age 40, whereas the peak in Canada is between the ages of 65 and 70 . The maximum value for U.S. males is about $\$ 0.55$ (implying a VSLY of \$550,000), but the values range from $\$ 0.47$ at age 25 to $\$ 0.02$ at age 80 . For U.S. females, the maximum value is only about $\$ 0.30$, although the estimates range from $\$ 0.25$ at age 25 to $\$ 0.08$ at age 80 . Canadian values peak later, at about age 65 to 70 . The peak for Canadian males is about $\$ 0.57$, whereas the peak for Canadian females is only about \$0.19.

The VSLY numbers implied by our simulations can be compared to those produced in Aldy and Viscusi (2008). For the U.S., our peaks for males of $\$ 550,000$ (in 2003 U.S. dollars) and for females of $\$ 300,000$ occur at about age 40. Aldy and Viscusi's basic measure (calculated for a discount rate of 3\%, rather than our 5\% rate) peaks at a value of $\$ 375,000$ at age 45 . Their cohort-adjusted measure peaks at a value of \$401,000 (in year 2000 dollars) at age 54. Aldy and Viscusi's sample is limited to workers and appears to include both males and females without differentiation, so that one would expect the peak to be lower for their data (since their model pools both genders and uses earlier dollars) than for our results for U.S. males. Thus our results for a construct similar to the VSLY seem reasonably consistent with those of Aldy and Viscusi (2008).

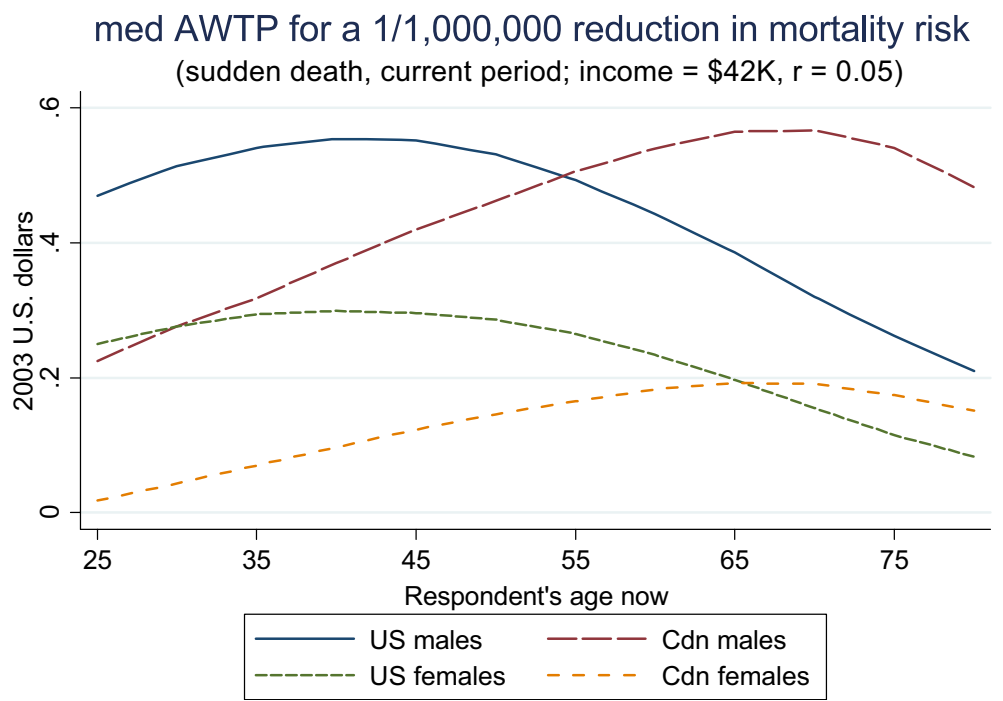

Fig. 3 Male and female age profiles for median WTP per discounted lost life-year, in the U.S. and Canada (see Appendix III for 5th and 95th percent intervals around each median. Appendices available online at http://pages.uoregon.edu/cameron/JRU/CDS_Appendices.pdf) 


\subsection{Heterogeneity in age profiles for $W T P_{\mu r}$}

Returning to the overall $W T P_{\mu r}$ estimates, we can consider other sources of heterogeneity besides age by looking at additional factors which shift the age profile of $W T P_{\mu r}$. We have already shown that males in the U.S. sample are willing to pay more for health risk reduction programs. The age profiles in Appendices II through VI show that respondents who are married and have a college degree tend to have substantially higher $W T P_{\mu r}$ than non-college-educated and unmarried respondents in the U.S., but not in Canada. Peak median $W T P_{\mu r}$ for college-educated males in the U.S. is about $\$ 13.59$, and for unmarried males in the U.S. it is only $\$ 7.62$ (both at about age 35). By contrast, peak median $W T P_{\mu r}$ is $\$ 8.55$ for college-educated males in Canada, and $\$ 8.99$ for those who are unmarried (both at about age 55).

A notable result is that the difference between peak Canadian male $W T P_{\mu r}$ and peak U.S. male $W T P_{\mu r}$ amounts is reduced substantially by Canadian experience with out-of-plan medical diagnostic tests. Peak median WTP for Canadian males with out-of-plan experience jumps to $\$ 11.89$ (at about age 60 ), with a fairly wide confidence band, and is well within the $90 \%$ interval for the U.S. peak for males at age $35-40$.

\section{Conclusions}

This study has shown that failure to control for individual heterogeneity, in the presence of different types of respondents in the U.S. and Canada, can easily distort the coefficients on the interaction terms involving the indicator for the Canadian subsample. Different patterns in sociodemographic and attitudinal heterogeneity across the two countries account for a good deal of heterogeneity in choice behavior in our study, but there remain many dimensions where there are further differences that we can so far attribute only to the difference in jurisdictions. Of course, there may still be other factors which differ across jurisdictions (e.g. other cultural differences) which we have not observed in this study and are therefore unable to use as controls.

The insights from our analysis raise many important questions about differences between the U.S. and Canada in individual demands for health-maintenance programs (and, by analogy, reductions in environmental health risks). As always, further independent research will help add to the weight of evidence concerning our findings, but our results seem to suggest the following.

For Canadians, experience with private health care options outside their provincial health plans may be correlated with preferences that correspond more closely to those held by U.S. residents. Some Canadians worry that encroachment of private health care options in Canada will spoil universal health care. Thus there may be reason to worry that people who self-select to go outside their provincial plans may already have preferences more like U.S. preferences.

Canada's provincial health plans mean that the implicit annual value of this health insurance is not included in measured income. Canadians' lower willingness to pay for health risk reductions in this study might seem lower yet if these amounts were associated with incomes that were actually higher by the implicit value of the 
publicly provided health coverage. Peak willingness to pay for mortality risk reductions also occurs at much older ages in Canada, even controlling for a wide range of other attitudinal and subjective risk factors that are correlated with age to some extent.

Until they reach age 60, Canadians appear to be generally less confident that they will receive timely and effective medical care, compared to their U.S. counterparts, but their confidence levels seem to increase markedly after age 60. Despite this lack of confidence among younger Canadians, compared to U.S. residents, these respondents do not feel as much like they could improve their health habits by seeing a doctor more regularly. Thus, despite the perception in the U.S. that the Canadian health care system involves long queues and delays in seeing specialists, Canadians may not feel that they see their primary care physicians too infrequently.

Greater confidence in the timeliness and efficacy of health care, for Canadians, tends to reduce their average willingness to pay for diagnostic testing programs to reduce the risk of lost life-years. In the U.S., however, greater confidence seems to increase willingness to pay for these same types of programs. This may reflect different attitudes towards preventive medicine. Canadians may view it as a substitute for later treatment, while U.S. residents may see preventive testing as a complement to treatment.

Finally, our results may explain different expectations, across the two countries, concerning entitlement to end-of-life interventions without regard to cost. The effect of additional years of pre-mortality morbidity on an individual's willingness to pay to reduce the risk of lost life-years appears to have the opposite sign in the U.S. and Canada. Additional prior morbidity appears to raise WTP for mortality risk reductions in the U.S., but lowers it in Canada.

Acknowledgements We received helpful advice on this project from Mary Evans, Didier Tatoutchoup, Diane Dupont and participants at the October 2008 meeting of the CREESG at Ryerson University, from participants at the 2009 WEAI/AERE sessions in Vancouver, from Vic Adamowicz and other participants at the October 2009 CREESG meeting at the University of Alberta, Canada, as well as Glenn Blomquist and other participants at the June 2010 ASHEcon meeting at Cornell University. Kip Viscusi and an anonymous referee have also provided valuable advice. This research has been supported by a grant from the National Science Foundation (SES-0551009) to the University of Oregon (PI: Trudy Ann Cameron). It employs original survey data from an earlier project supported by the U.S. Environmental Protection Agency (R829485) and Health Canada (Contract H5431-010041/001/SS) at UCLA (PI: J.R. DeShazo). Additional support has been provided by the Raymond F. Mikesell Foundation at the University of Oregon. Office of Human Subjects Compliance approval filed as protocol \#C4-380-07F at the University of Oregon. This work has not been formally reviewed by any of the sponsoring agencies. Any remaining errors are our own.

Open Access This article is distributed under the terms of the Creative Commons Attribution Noncommercial License which permits any noncommercial use, distribution, and reproduction in any medium, provided the original author(s) and source are credited.

\section{References}

Alberini, A., Cropper, M., Krupnick, A., \& Simon, N. B. (2004). Does the value of a statistical life vary with age and health status? Evidence from the US and Canada. Journal of Environmental Economics and Management, 48(1), 769-792. 
Aldy, J. E., \& Viscusi, W. K. (2007). Age differences in the value of statistical life: revealed preference evidence. Review of Environmental Economics and Policy, 1(2), 241-260.

Aldy, J. E., \& Viscusi, W. K. (2008). Adjusting the value of a statistical life for age and cohort effects. The Review of Economics and Statistics, 90(3), 573-581.

Baker, R., Chilton, S., Jones-Lee, M., \& Metcalf, H. (2008). Valuing lives equally: defensible premise or unwarranted compromise? Journal of Risk and Uncertainty, 36(2), 125-138.

Cameron, T. A. (2010). Euthanizing the value of a statistical life. Review of Environmental Economics and Policy.

Cameron, T. A., \& DeShazo, J. R. (2009). Demand for health risk reductions, Department of Economics. University of Oregon Working Paper.

Cameron, T. A., DeShazo, J. R., \& Johnson, E. H. (2007). 'Scenario adjustment' in stated preference research. Department of Economics, University of Oregon Working Paper.

Cameron, T. A., DeShazo, J. R., \& Johnson, E. H. (2008). Willingness to pay for health risk reductions: Differences by type of illness. Department of Economics, University of Oregon.

Chestnut, L. G., \& De Civita, P. (2009). Economic valuation of mortality risk reduction: Review and recommendations for policy and regulatory analysis. PRI Project, Regulatory Strategy.

Chestnut, L. G., Rowe, R. D., Lazo, J. K., \& Breffle, W. S. (2003). Economic valuation of mortality risk reduction: Stated preference approach. Stratus Consulting.

Chestnut, L. G., Rowe, R. D., \& Breffle, W. S. (2004). Economic valuation of mortality risk reduction: Stated preference approach in Canada. Boulder: Stratus Consulting, Inc.

Chestnut, L. G., Rowe, R. D., \& Breffle, W. S. (2009). Economic valuation of mortality risk reduction: Stated preference estimates from the United States and Canada. Boulder: Stratus Consulting.

DeShazo, J. R., \& Cameron, T. A. (2005). Two types of age effects in the demand for reductions in mortality risks with differing latencies. Working Paper, Department of Economics, University of Oregon.

Dreze, J. (1962). L'utilite sociale d'une vie humaine. Revue Francaise de Recherche Operationalle, 93118.

Graham, D. A. (1981). Cost-benefit-analysis under uncertainty. The American Economic Review, 71(4), $715-725$.

Hammitt, J. K. (2007). Valuing changes in mortality risk: lives saved versus life years saved. Review of Environmental Economics and Policy, 1(2), 228-240.

Jones-Lee, M. (1974). The value of changes in the probability of death or injury. Journal of Political Economy, 82(4), 835-849.

Kochi, I., Hubbell, B., \& Kramer, R. (2006). An empirical Bayes approach to combining and comparing estimates of the value of a statistical life for environmental policy analysis. Environmental \& Resource Economics, 34(3), 385-406.

Krupnick, A. (2007). Mortality-risk valuation and age: stated preference evidence. Review of Environmental Economics and Policy, 1(2), 261-282.

Krupnick, A., Alberini, A., Cropper, M., Simon, N., O’Brien, B., Goeree, R., et al. (2002). Age, health and the willingness to pay for mortality risk reductions: a contingent valuation survey of Ontario residents. Journal of Risk and Uncertainty, 24(2), 161-186.

List, J. A. (2001) Do explicit warnings eliminate the hypothetical bias in elicitation procedures? Evidence from field auctions for sportcards. American Economic Review, 91(5), 1498-1507.

Moore, M. J., \& Viscusi, W. K. (1988). The quantity-adjusted value of life. Economic Inquiry, 26(3), 369388.

Mrozek, J. R., \& Taylor, L. O. (2002). What determines the value of life? A meta-analysis. Journal of Policy Analysis and Management, 21(2), 253-270.

Sunstein, C. R. (2003). Lives, life-years, and the willingness to pay. Columbia Law Review, 104, 205-252.

Sunstein, C. R. (2004). Valuing life: a plea for disaggregation. Duke Law Journal, 54(2), 385-445.

Van Houtven, G., Sullivan, M. B., \& Dockins, C. (2008). Cancer premiums and latency effects: a risk tradeoff approach for valuing reductions in fatal cancer risks. Journal of Risk and Uncertainty, 36(2), 179-199.

Viscusi, W. K. (1993). The value of risks to life and health. Journal of Economic Literature, 31, 19121946.

Viscusi, W. K., \& Aldy, J. E. (2003). The value of a statistical life: a critical review of market estimates throughout the world. Journal of Risk and Uncertainty, 27(1), 5-76.

Viscusi, W. K., \& Hersch, J. (2008). The mortality cost to smokers. Journal of Health Economics, 27(4), 943-958. 